Acta Poetica $26(1-2)$

PRIMAVERA-OTOÑO

2005

\title{
El romance: transmisión oral y transmisión escrita
}

\begin{abstract}
Aurelio González
Desde los primeros textos que se publicaron del Romancero viejo, tomados de la tradición oral y escrita, el romance ha tenido una intensa vida tradicional y un riquísimo proceso de variación que lo convierte en uno de los más extraordinarios ejemplos de pervivencia de la balada internacional. Pero también a lo largo de los siglos de su vida en la memoria colectiva y en la recreación de la transmisión oral, la existencia de versiones que se han conservado por escrito y el propio hecho de una transmisión escrita han marcado su pervivencia. En el trabajo se señalan algunos puntos importantes en esta doble tradición, como las ediciones de Martín Nucio, los pliegos sueltos, "Flor nueva" y las inclusiones en libros de texto escolares.

Since the first texts of the Roman Viejo were published, ballads from oral and written tradition have had an intense traditional life and a complex variation process. We may consider them as most extraordinary examples of international ballad survival (determined both by its life in the collective memory and by a written transmission). This paper deals with some important issues concerning this double transmission, such as Martin Nuncio's editions, chapbooks, "Flor Nueva" and their inclusion in school textbooks.
\end{abstract}


Acta Poetica 26 (1-2)

PRIMAVERA-OTOÑO

2005

Aurelio González

El Colegio de México

\section{El romance: transmisión oral y transmisión escrita}

La obra literaria de tradición oral no se puede concebir como tal en el momento de su creación, sea quien sea su autor, tal como sucede en otros tipos de literatura, sino en el momento en que, por estar acorde con una estética colectiva - la que comparte, valora y acepta una comunidad-, ésta la acepta y la mantiene viva a través de todas y cada una de sus distintas objetivaciones o realizaciones individuales, mismas que son variables, y a las cuales conocemos con el término de versiones.

Por lo tanto, un texto compuesto como obra literaria culta puede entrar a la cadena de transmisión oral y sólo en este proceso es que adquiere las características del lenguaje tradicional oral. Así sucede por lo general con textos que tienen afinidades, ya sean temáticas, formales o estructurales con géneros arraigados en la comunidad. Esto quiere decir que su composición se ha acercado a los rasgos de una estética colectiva.

Sin embargo, un texto puede transmitirse oralmente y no adquirir las características del lenguaje tradicional, esto es, transmitirse simplemente lexicalizado por un proceso de memorización, en cuyo caso no hay una creatividad por parte del transmisor. En este caso el texto puede querer decir algo para la comunidad, pero ésta no lo puede utilizar para expresar su 
sistema de valores y desde luego no podrá reformularizar el texto para adaptarlo a nuevas circunstancias. De esta manera, aunque el texto se escuentre en la cadena de transmisión oral, no podremos hablar exactamente de un texto de tradición oral. Esto es lo que sucede en muchas ocasiones, como por ejemplo con los himnos nacionales, composiciones cultas, por lo general, que se transmiten oralmente, y que por su lenguaje y características no son en realidad parte del patrimonio literario de la comunidad.

La aceptación del "texto" (que en el caso de que éste sea "tradicional" en realidad es solamente un modelo potencial que se realiza en las distintas versiones) por la comunidad se vuelve un hecho en el momento en que forma parte del acervo comunitario; es decir, parte del acervo individual de cada uno de los distintos transmisores de la comunidad. Además, hay que tomar en cuenta que no todos los individuos de una comunidad — depositarios de una versión, que ya no del "texto"actúan de la misma manera. La mayoría serán depositarios y transmisores que se pueden definir como pasivos: no se apasionan por las historias que cuentan, no buscan su conocimiento, lo reciben circunstancialmente, y por eso el acervo de "textos" que conocen es relativamente limitado; las "historias" que poseen están expresadas en un lenguaje del que son "hablantes" naturales, pero su ejercicio de este lenguaje en cada objetivación del relato no llega casi nunca a rebasar los límites propios de la relación lengua-habla.

Existen otros transmisores, sin embargo, que son los verdaderos recreadores, poseedores de acervos amplios por el dominio que tienen del lenguaje tradicional $\mathrm{y}$, por lo mismo, realmente hacedores, es decir, "poetas" de la tradición oral, capaces de conservar el texto y remodelarlo poéticamente en el momento en que lo integran en su memoria. ${ }^{1}$ Asimismo es-

\footnotetext{
${ }^{1}$ Sobre este punto no todos los especialistas están de acuerdo, ya que algunos piensan que la remodelación poética o variación se da en el momento de la obje-
} 
tos poetas pueden establecer una interrelación entre lo individual y lo comunitario. Para decirlo con palabras de la investigadora Ruth Finnegan: "the oral poet is not merely the voice of communal pressures, neither is every poet an individual and untrammelled genius: poetry is the creation both of a particular community and of a particular individual" (Finnegan 1977, 213).

La especificidad de la literatura llamada oral (en realidad, “de transmisión oral") no radica entonces solamente en su forma de transmisión (por la voz), sino también en que está compuesta de acuerdo con unos principios particulares, que no son los mismos de la literatura considerada culta. Con lo cual por oral no se deberá entender simplemente lo contrario de escrito, sino una forma específica de creación literaria y de cultura.

Podemos considerar que el proceso de transmisión oral está integrado por los siguientes pasos:

a) composición (oral o escrita) en algún momento indeterminado y, a fin de cuentas, poco importante una vez que el "texto" forma parte del saber de la comunidad;

b) objetivación (ejecución-recepción, performance) ${ }^{2}$

c) fijación por la memoria y, nuevamente, ejecución (Zumthor 1979, 519).

El texto oral existe en forma concreta solamente en el momento en que un miembro de la comunidad lo ejecuta, para sí mismo o ante algún escucha. Esto implica una serie de dificul-

tivación o performance del texto. Pero esta posición me parece más difícil de sostener. Mi experiencia me ha demostrado que el transmisor por lo general posee $s u$ versión, o cuando mucho dos versiones (normalmente en este caso una de ellas es tradicional, y la otra, lexicalizada, bien sea de origen libresco, o bien una vulgata). Para el transmisor sería muy complicado mantener la fijeza de su versión si la rehiciera en el momento de cada ejecución (performance). Los transmisores excepcionales, creativos, con real dominio del lenguaje tradicional, si hacen variaciones en el momento de la ejecución, las hacen sobre su propio patrón narrativo del texto que ya poseen con anterioridad.

${ }^{2}$ Este término en inglés se usa cada vez con más frecuencia para indicar el acto complejo en que coinciden la transmisión (en forma oral) y la recepción (en forma auditiva) en el momento de la ejecución del texto. 
tades que no se presentan con la lectura del texto escrito, pues, como bien ha dicho Zumthor:

La performance orale implique une traversée du discours par la mémoire, toujours aléatoire et trompeuse, déviante en quelque façon; d'où les variations, les modulations improvisées, la re-création du déjà-dit, la répétitivité: aucune globalité n'est perceptible, à moins que le message ne soit très bref. (Zumthor 1979, 521)

Por otra parte, el hecho mismo de dicho tipo de performance implica la participación amplia de los sentidos y de las circunstancias variables en que este acto complejo se lleva a cabo, todo lo cual contribuye a completar, con elementos suprasegmentales y contextuales, el significado del texto de una forma totalizadora, que rebasa el nivel de lo que se puede entender cuando sólo se conoce la versión del texto objetivado por el transmisor durante una ejecución. El carácter efímero de cada variante, o sea la inestabilidad textual definitoria de la literatura de transmisión oral debida a su "apertura", significa que nunca se agotan las posibilidades de variación de un "texto", entendido éste como el cañamazo del que hablan Jakobson y Bogatyrev. ${ }^{3}$ Por eso mismo, para ahondar realmente en la significación de un texto tradicional en su contexto histórico y social, quienes lo abordamos desde fuera de la comunidad en que éste vive y se desarrolla, debemos hacernos del mayor número de versiones posibles, sin olvidar que jamás lograremos conocerlas todas.

Esta forma de concebir $-\mathrm{y}$ producir - el hecho literario fue fundamental, y en muchos casos la única, durante gran parte de la historia literaria de la Humanidad. ¿Cuántos textos

\footnotetext{
${ }^{3}$ El texto es "extrapersonal y tiene sólo existencia potencial. No es sino un complejo de normas e impulsos determinados, un cañamazo de tradición actual que los intérpretes animan con los adornos de su creación individual, como lo hacen los generadores del habla con respecto a la lengua" (Jakobson y Bogatyrev 1977, 12-13).
} 
del mundo helénico o de la Edad Media, hoy sacralizados como textos únicos, no son sino versiones desgajadas de la cadena tradicional? Al hombre culto de nuestros días, sumergido en la producción literaria industrial post-gutenbergense, muchas veces le cuesta trabajo entender el proceso de una literatura en la cual no hay una clara diferenciación entre el emisor y el receptor, donde la originalidad y la exclusividad son términos casi sin sentido. ${ }^{4}$ Sin embargo, no hay que olvidar que, aun en nuestros días, la mayor parte de los seres humanos disfrutan de una literatura exclusivamente de este tipo, la misma que ha existido desde que los primeros hombres decidieron que un relato tenía valor y merecía conservarse por contener algo distinto de la simple comunicación cotidiana.

Con lo anterior no negamos la convivencia de ambas formas de literatura, hoy y en otras épocas, en determinados ámbitos, ni pretendemos comparar sus méritos o valores. Simplemente, queremos poner de manifiesto la existencia de una especificidad de la literatura de transmisión oral y lo erróneo de aplicarle indiscriminadamente los criterios de la literatura culta, ya que, además de su distinto proceso de transmisión, está formada por elementos que, aunque en ocasiones son similares, se organizan de manera diferente. Para decirlo en palabras de Jakobson y Bogatyrev,

sería ambiguo hablar de formas idénticas a propósito de folklore y literatura [entendida en su forma culta]. Así, pongamos por caso, el verso, concepto que a primera vista parece significar lo mismo, tanto en literatura como en folklore, cubre aspectos en realidad muy diferentes en el plano funcional. (Jakobson y Bogatyrev, 1977, 19)

Desde hace mucho tiempo no podemos hablar de una "oralidad primaria", ya que los textos, culturalmente hablando, pa-

${ }^{4}$ Sobre este problema véase la presentación de Diego Catalán (1984, 13-15). 
san de un registro oral a uno escrito y viceversa. ${ }^{5}$ Desde la Edad Media ambos procesos de transmisión interactúan en la realización del hecho literario. Además, nuestro conocimiento de los textos de transmisión oral del pasado proviene de su registro escrito; registro que en las distintas épocas ha correspondido a principios, ideas y objetivos muy variados, que en muchos casos no valoran la conservación del texto tradicional en sí mismo, adaptándolo para que coincida con una idea o ideología concreta. En la Edad Media multitud de autores recogían los cuentos y demás textos transmitidos oralmente, lo mismo hizo Erasmo y los editores del siglo XVI. En lo que se refiere a las baladas, McPherson recogió las canciones escocesas en el siglo XVIII y lo mismo hicieron después Percy y Child.

Así como no podemos hablar en el mundo moderno de una "oralidad primaria", las mismas circunstancias hacen que en muchos casos tengamos que hablar de una "memoria transcrita". 6 Es claro que si un texto ha tenido que ser aceptado por la comunidad para formar parte del acervo oral, debe ser tomado en cuenta no sólo en sus aspectos formales sino también en su contenido. Pues también existe una relación más o menos profunda entre contexto y contenido que prolonga en el tiempo, no sólo una tradición literaria, sino también una tradición ideológica. La presencia de

elementos que apuntan a un mundo inactual, no es contradictoria con la actualidad permanente de sus mensajes. La presencia de esos significantes arcaicos no responde a un interés 'histórico' (más bien sería 'arqueológico') por unas estructuras políticas, sociales e ideológicas caducadas... (Catalán 1984, 21)

\footnotetext{
5 Walter Ong entiende por oralidad primaria "la oralidad de una cultura que carece de todo conocimiento de la escritura o de la impresión" (1987, 20).

6 Tomo el término de Viviane Sukanda-Tessier quien habla de "mémoire orale pure", "mémoire soutenue" y "mémoire transcrite" que es aquella en la que interviene la tradición escrita $(1998,51)$.
} 
sino, como explica el mismo Catalán, a la presentación de un mundo alternativo que permite soluciones que en el mundo real serían demasiado subversivas.

Un mismo poema, gracias a la apertura que caracteriza a este ámbito literario, podrá reactualizar su sentido, a veces gracias a variantes mínimas, para adaptarse a las instituciones y situaciones vigentes de la comunidad en la cual se reproduce. Muchas veces, la acronía (entendida como atemporalidad o temporalidad anacrónica) permite el planteamiento de opciones renovadoras de la sociedad al explicar, a través del relato actualizado, las condiciones y costumbres del contexto en el cual vive un texto determinado. Esto es posible gracias a esa doble condición que posee el texto oral, que, por una parte, es un vigoroso soporte de la tradición, y, simultáneamente, permite, por ausencia de fijeza, una expresión riquísima de la innovación.

Veamos ahora cómo ha interactuado la escritura en el conocimiento y difusión de textos romancísticos de tradición oral. El Romancero nace a finales del siglo XIII o principios del XIV, iniciando una trayectoria que perdura hasta nuestros días. A lo largo de los dos últimos siglos de la Edad Media tendrán vitalidad los cantos romancísticos derivados de los grandes cantos épicos, las novedades provenientes de la baladística europea y los romances fronterizos noticiosos. No se debe dejar a un lado el valor del Romancero como instrumento propagandístico por ejemplo en el conflicto entre el rey don Pedro I el Cruel y su hermano don Enrique (1358-1369); sin embargo, ya en los tiempos de la corte de Juan II, a mediados del siglo Xv, los romances no tienen ningún aprecio como forma literaria. Para Juan de Mena, por ejemplo, el romance era una forma de canto privativa de los campesinos y el Marqués de Santillana califica, en 1445, en su Proemio e carta al Condestable de Portugal, como textos poéticos ínfimos "aquellos que sin ningund orden, regla nin cuento, fazen estos romançes e cantares de que 
las gentes de baxa e servil condiçión se alegran" (Marqués de Santillana 1991, t. II, 335).

A pesar de este desprecio, los últimos años del siglo XV son muy importantes no sólo políticamente, sino también por la proyección de la cultura medieval. Por ejemplo, en el caso del Romancero, "la última etapa creadora del romance fronterizo viejo coincide con el largo reinado de los Reyes Católicos donde los procesos y caminos de transmisión se multiplican hasta el infinito así como los actos creadores de un romance" (Correa 1999, t. I, 33). Durante esta época el romance sigue con una vida intensa en los sectores populares de la sociedad, y con una rica transmisión oral, pero al mismo tiempo adquiere auge y reconocimiento en los ambientes cortesanos. El romance ahora lo comparten los juglares y los nobles compositores de la corte; se incorpora a las vías de difusión que ofrece la recién desarrollada imprenta de tipos móviles, que muy pronto serán aprovechadas por los editores para satisfacer los gustos de una sociedad para la que el romance había sido y seguía siendo un medio noticiero importantísimo.

En 1421, un estudiante mallorquín en Italia, Jaume de Olesa, al transcribir en un cuaderno el romance de La dama y el pastor, fija por primera ocasión, por lo que nosotros sabemos, un texto romancístico que hasta ese momento había vivido sólo en la memoria colectiva, en las múltiples variantes de tradición oral. ${ }^{7}$ Desde luego podemos suponer, y casi no tener duda de que esto haya sucedido, que alguien más en cualquier otro momento pudo haber puesto por escrito un romance; pero el texto de Olesa es importante, ya que representa documentalmente, por vez primera, el fenómeno de la fijación por escrito de una versión romancística tradicional. La ausencia de documentos nos permite suponer que el Romancero vive durante mucho tiempo como un texto casi exclusivamente de tradición

${ }^{7}$ Levi 1927, 134-160 y Catalán et al., 1977-1978. 
oral, ya que no sería lógico suponer que el amplio corpus que después se compilaría, y en el cual están incluidos textos que se refieren a acontecimientos históricos sucedidos dos o más siglos antes, fuera compuesto en la época en que se reunían las primeras colecciones de romances en el siglo XVI; o por el contrario, suponer que tuviera una amplia transmisión escrita y que se hubieran perdido casi todos los documentos. Por otra parte, como hemos señalado antes, el texto tradicional se caracteriza por vivir en variantes, y en esas primeras colecciones romancísticas en varias ocasiones nos encontramos con la existencia de distintas versiones de un mismo romance, cuyas variaciones no podríamos explicar solamente con el trabajo de retoque de los impresores.

Esta vida oral del romance en los siglos XV y XVI la atestiguan también las afirmaciones de los primeros editores de romanceros, quienes fijan el texto al ponerlo por escrito, y reconocen la oralidad del mismo cuando dicen que lo han recogido de las voces populares y que lo han modificado, como lo afirma Martín Nuncio en su preámbulo a la edición del Cancionero de romances de 1550:

He querido tomar el trabajo de juntar en este cancionero todos los romances que han venido a mi noticia... no niego que en los que aqui van impressos aura alguna falta pero esta se deue imputar alos exemplares de adonde los saque que estauan muy corruptos: y ala flaqueza dela memoria de algunos que me los dictaron que no se podian acordar dellos perfectamente. Yo hize toda diligencia porque vuiesse las menos faltas que fuesse possible y no me ha sido poco trabajo juntarlos y enmendar y añadir algunos que estauan imperfectos [...]. (Cancionero de romances 1967, 109)

Podemos decir que estos editores fijan su texto desde el momento en que sus versiones están modificadas por su gusto personal — que corresponde al de la época—, ya que hay un 
distanciamiento tanto respecto a lo que recogen directamente de la tradición oral como a lo que seleccionan de cartapacios manuscritos. Estas versiones publicadas adquieren un prestigio mayor y distinto (el que da la letra impresa) y tienen un vehículo de difusión diferente (pliegos sueltos y cancioneros) que hará más difícil el proceso de variación por parte del posible receptor, pero que a su vez, por el prestigio mencionado pueden incidir en privilegiar ciertas variantes.

Por otra parte hay que recordar también que el mencionado romance de La dama y el pastor es un caso extremo de relación entre géneros y modelos, pues existe un romance viejo, luego otro nuevo que se refundió en villancico del cual derivan todas las versiones españolas tradicionales modernas, al contrario de lo que sucede entre los sefardíes donde se encuentran muchas versiones que derivan del romance.

La imprenta de tipos móviles se establece en España en torno a 1475 y gracias a ella se posibilitará la difusión escrita de los romances de forma masiva (gracias a que los impresos tenían un precio al alcance de las mayorías). Es claro que se trataba de materiales muy sencillos y perecederos: simples hojas dobladas sin cortar, los muy populares pliegos sueltos.

Se trata de un momento crucial en el que conviven por primera vez dos formas distintas de transmisión - la escritura, masiva por ser impresa, y la oralidad- de un mismo género de gran popularidad y por tanto de aceptación en todos los niveles sociales: el Romancero.

Es evidente que los pliegos sueltos son un tipo de publicaciones que va dirigido a un público distinto del que tenía acceso económico (o interés) por los cancioneros. La publicación era más popular y tenía una vida efímera, se gastaba de mano en mano. A pesar de ser un soporte escrito, el pliego es un testimonio importante de la vitalidad de la tradición romancística. El pliego suelto con romances más antiguo del que tenemos noticia se publicó en Zaragoza en la imprenta de Jorge Coci 
hacia 1506, y contiene el Romance del palmero (La aparición) y Los doce pares de Francia (Baldovinos y Roldán). Esta imprenta después publicará, entre muchos otros, los romances del Conde Dirlos (1510) y del Conde Alarcos (1520). Otra de las primeras imprentas en hacer pliegos sueltos romancísticos fue la de Jacobo Cromberger de Sevilla, conocida por su importancia en el envío de toda clase de publicaciones al Nuevo Mundo. Algunas imprentas que le siguen en importancia son la de Fadrique de Basilea en Burgos (1516), que en un principio se dedica a romances carolingios y novelescos, y la de Carles Amorós en Barcelona (1525). Los pliegos sueltos conocidos en nuestros tiempos pasan de 1200, siendo fundamentales para el Romancero viejo más de 200 (Di Stefano 1977). En los pliegos sueltos se encuentra una proporción mayor de romances de tema novelesco o caballeresco que de temas históricos y épicos, al contrario de lo que sucede en los cancioneros.

Las publicaciones que tienen un sentido de permanencia y ven el género en su conjunto son los "cancioneros" del siglo $\mathrm{XVI}$, sobre todo los Cancioneros de romances publicados en torno a 1550 por Martín Nucio en Amberes y la Silva de romances publicada en Zaragoza en 1550. Este tipo de colecciones se prolongará hasta las Rosas de romances, publicadas por Joan Timoneda en Valencia en 1573, o la Silva de varios romances (Barcelona, 1581). A lo largo del siglo XVI se imprimieron 54 Cancioneros y Romanceros con un total de 105 ediciones.

En esta época de claro desarrollo de la letra impresa, también se mantienen vivos en el gusto general los romances de tono más tradicional, más cercanos a la oralidad, como $L a$ pérdida de Alhama, cuya historia se centra más en la pérdida de la ciudad, vista desde la óptica musulmana, que en la hazaña de algún noble. Por ejemplo, de este romance nos han llegado tres versiones, una más larga con la mención de quienes 
iniciaron el ataque y del intento de reconquistarla, muy difundida en los cancioneros y romanceros, y otras dos, de tono más tradicional, recogidas tiempo después por Pérez de Hita en sus Guerras civiles de Granada. En ellas no aparecen las acciones de Rodrigo Ponce de León, marqués de Cádiz, y de Martín Galindo, y se limitan a narrar la pérdida de la ciudad con un tono de lamento elegíaco —que la crítica, especialmente en el siglo XIX quiso ver románticamente como trasunto de los cantos musulmanes por la pérdida de ciudades, tal como había dicho Pérez de Hita en su novela-. Este romance también es famoso por su estribillo “Ay, de mi Alhama” muy popular entre los músicos:

Passeávase el Rey Moro por la ciudad de Granada, desde las puertas de Elvira hasta las de Bivarambla.

(Ay de mi Alhama!)

Cartas le fueron venidas que Alhama era ganada:

las cartas echó en el fuego, y al mensagero matara.

(Ay de mi Alhama!)

En el siglo XVI este romance es el más popular (después del de Conde Claros) entre los vihuelistas de la época y como tal aparece en el libro Delphín de Música de Luis de Narváez (1538), en el Libro de música de vihuela (1552) de Diego Pisador, igual que en Fuenllana y Vanegas y varios más. El trabajo de los músicos de esta época tiene que ver con la escritura, edición y publicación, así también su labor es muy importante con los textos romancísticos tanto en su transmisión como recreación y aceptación en los círculos cortesanos.

Con la rápida difusión de la imprenta, los romances se alejan de la antigua oralidad convirtiéndose en textos para ser leídos. En este momento, motivadas por el gusto del público en general y también por editores buscando novedades, se introducen modificaciones formales en los romances. Aparece el gusto por el fragmentarismo y se tiende a dividir los roman- 
ces en cuartetas y a insertar en ellos fragmentos líricos (villancicos o canciones), muchas veces al final como desfecha, es decir, una versión condensada del texto en su conjunto.

Margit Frenk ha señalado que muchas veces no se ha reparado en un fenómeno que distingue la difusión escrita del Romancero de la difusión de otros géneros como la lírica: la manera en que circularon y se divulgaron en la cultura urbana y cortesana de los Siglos de Oro. Se puede "decir que la difusión escrita de los romances fue más especializada y también que la lírica popular, a la par que la no popular, se difundió más a través de manuscritos que de impresos" (Frenk 2001, n. 53).

Después del intermedio del siglo XVIII con su no valoración de lo popular debida al neoclasicismo y a la Ilustración, la recolección de los textos romancísticos de la tradición oral moderna se inicia en el área portuguesa hacia 1823 con la "señora de Lisboa", a quien Almeida Garrett encarga, desde Inglaterra, que recoja las viejas baladas "romances", según el modelo de lo que había conocido bajo el influjo de la lectura de Walter Scott y con la intención de hacer lo mismo. Pero el resultado, publicado en Londres en 1828, son casi notas a las propias composiciones-refundiciones -Adozinda y Bernal Francésdonde se resalta, muy en las ideas del Romanticismo, lo que es la voz del pueblo. Garrett publicará su Romanceiro en 1843, pero él "no espera ser leído por los sabios, sumidos en prejuicios; le basta con ser gustado por los jóvenes y las mujeres" (Menéndez Pidal 1968, t. II, 271).

Todos estos recolectores no podían sustraerse a la tentación de corregir, afinar y mejorar las versiones recogidas de la tradición oral. Esto tal vez porque partían de una idea estética y, en muchos casos, incluso de un pensamiento nacionalista que los llevaba al extremo de falsificar versiones. Lo mismo sucede en España con figuras tan encomiables como José Amador de los Ríos, quien en 1840 presentó ante la Academia Sevillana de Buenas Letras un discurso sobre los romances 
castellanos. La recolección romancística importante la realiza en Asturias en 1860 y 1864. Sin embargo, sus textos fueron muy arreglados literariamente en un proceso de embellecimiento y arcaización y, aunque permanecieron inéditos en su mayor parte, algunos, ocho, llegaron a nosotros en la publicación de Juan Menéndez Pidal (1885). Amador de los Ríos se quejaba de los efectos altamente perjudiciales de los romances vulgares, transmitidos por pliegos sueltos para el mantenimiento de la auténtica poesía popular, olvidando la interrelación que existe entre la imprenta, la escritura y la transmisión oral, no solamente en el mundo contemporáneo sino también en la antigüedad. Es muy posible que la presencia escrita de estos textos tuviera influencia en la configuración del gusto por los romances en determinados círculos, aunque posiblemente no en aquellos en los cuales la transmisión oral es natural.

En la tradición oral moderna del siglo xx tenemos el ejemplo del proceso, en un ciclo completo de interrelación de la transmisión oral y la escrita, de contacto de ambas transmisiones. Me refiero al caso de Flor nueva de romances viejos, libro de divulgación preparado por Ramón Menéndez Pidal en 1928 (Madrid, La Lectura) y revisado en 1933 ("2a versión comentada") que contiene versiones facticias preparadas a partir de las versiones de tradición oral, con añadidos del propio Menéndez Pidal. Esta publicación tuvo una difusión extraordinaria en todo el mundo hispánico, sobre todo a partir de las ediciones de Espasa Calpe (Madrid, 1938 y Buenos Aires, 1943) en la colección Austral (el emblemático número 100), las cuales se siguen reeditando hasta nuestros días. Pero el público entre el que circuló, especialmente en España, no fue solamente aquel que acude a librerías y que por lo tanto pertenece al ámbito culto, sino que tuvo muy buena acogida en el entorno rural. De esta manera, las versiones facticias de la publicación regresaron al circuito de la tradición oral ini- 
ciando un nuevo proceso que podríamos decir de "retradicionalización" en el cual los transmisores pulieron las aristas que había dejado don Ramón. ${ }^{8}$

Aunque como hemos dicho al principio, el texto de tradición oral tiene unas características específicas en su composición, derivadas de su forma de transmisión y de tener por soporte la memoria colectiva, eso no quiere decir que sea una isla al margen de su contexto cultural y hermético a los elementos circundantes. Hay una intercomunicación e interacción con las distintas formas culturales y de transmisión. En la comunicación oral pueden entrar textos ajenos a ella que pueden modificar el acervo cultural tradicional. Por otra parte, como ha dicho Antonio Cid, "todos conocemos casos en donde hay reintroducciones de modelos cultos, lo cual tiene enorme interés, aparte de que los textos quizás no sean válidos pero nos permiten ver cómo actúa a veces la tradición" (Cid 2001, 287).

En esta misma línea tenemos la influencia de tecnologías modernas como son las grabaciones. Un ejemplo es el caso de Antonio Mairena quien graba La pérdida de Alhama de Flor nueva al lado de versiones tradicionales. Incluso una de sus versiones grabadas, la de Bernardo al pie de la torre, influye en otros cantantes que crean variantes en una oralidad que Luis Suárez, recolector del romancero gitano ha llamado "atípica o bastarda”. Otro ejemplo son las extraordinarias grabaciones de romances de Joaquín Díaz que fácilmente desplazan las versiones tradicionales locales, en este caso por seguir un estilo tradicional y una estética colectiva, pero muy depuradas.

En síntesis podemos concluir recordando que "[...] la transmisión oral y la transmisión impresa han mantenido historias paralelas, sin que sus abundantes entrecruzamientos (que, en efecto, han existido siempre) anulen las diferencias específi-

\footnotetext{
${ }^{8}$ Sobre este proceso véase el excelente artículo sobre 21 versiones de La condesita derivadas de Flor nueva, recogidas entre 1946-1947 y 1970 en España y Marruecos de Ana Valenciano (2001, 175-193).
} 
cas entre ambos procesos de creación y transmisión literaria" (Cid 2001, 97).

\section{REFERENCIAS}

Cancionero de romances (Anvers, 1550), 1967. Antonio Rodríguez Moñino (ed), Madrid, Castalia.

Catalán, Diego, 1984. Catálogo general del Romancero pan-hispánico (CGR), Madrid, Seminario Menéndez Pidal-Gredos.

- et al., 1977-1978. La dama y el pastor. Romance, villancico, glosas, Madrid, Seminario Menéndez Pidal-Gredos, Madrid.

Cid, Jesús Antonio, 2001. "José Amador de los Ríos y el Romancero oral de la tradición moderna", en Los trigos ya van en flores. Studia in honorem Michelle Débax, Jean Alsina y Vincent Ozanam (coords.), Toulouse, CNRS - Université de Toulouse-Le Mirail, 83-101.

Correa, Pedro, 1999. Los romances fronterizos, t. I, Granada, Universidad de Granada, 2 vols.

Di Stefano, Giuseppe, 1977. "La difusión impresa del Romancero antiguo en el siglo XvI", Revista de Dialectología y Tradiciones Populares XXXIII, 373-411.

Finnegan, Ruth, 1977. Oral Poetry, Cambridge, Cambridge University Press.

Frenk, Margit, 2001. "El Romancero y la antigua lírica popular", en Pedro M. Piñero Ramírez, La eterna agonía del Romancero. Homenaje a Paul Bénichou, Sevilla, Fundación Machado.

JaKobson, Roman y Pietr Bogatyrev, 1977. "El folklore como forma específica de creación", en Ensayos de poética, México, Fondo de Cultura Económica, pp. 7-22.

Levi, Enzo, 1927. "El romance florentino de Jaume de Olesa", $R e$ vista de Filología Española XIV, 134-160.

Marqués de Santillana, 1991. Poesías completas, t. II, ed. de Miguel Ángel Pérez Priego, Madrid, Alhambra, 2 vols.

Menéndez Pidal, Ramón, 1968. Romancero hispánico. Teoría e historia, Madrid, Espasa-Calpe, $2^{\mathrm{a}}$ ed., t. II.

MenéndeZ PidAl, Juan, 1885. Viejos romances que se cantan por 
los asturianos en la Danza prima, esfoyazas y filandones recogidos directamente de boca del pueblo, Madrid, Hijos de J. A. García.

Nuncio, Martín, 1967. Cancionero de romances (Anvers, 1550), ed. de Antonio Rodríguez Moñino, Madrid, Castalia.

ONG, Walter, 1987. Oralidad y escritura. Tecnologías de la palabra, México, Fondo de Cultura Económica.

SukANDA-Tessier, Viviane, 1998. "La mémoire longue sunda", Cahiers de Littérature Orale 43, 51-93.

VAlenciano, Ana, 2001. "La conducta de la variación tradicional ante un texto de factura artificiosa: La condesita de Flor nueva", en Los trigos ya van en flores. Studia in honorem Michelle Débax, Jean Alsina y Vincent Ozanam (coords.), Toulouse, CNRS-Université de Toulouse-Le Mirail, pp. 175-193.

Zumthor, Paul, 1979. "Pour une poétique de la voix ", Poétique 40, 514-524. 